\title{
The Role of Tris in EDTA Toxicity and Lysozyme Lysis
}

\author{
By MILLICENT C. GOLDSCHMIDT* AND O. WYSS \\ Department of Microbiology, The University of Texas, \\ Austin, Texas, U.S.A.
}

(Accepted for publication 27 January 1967)

\begin{abstract}
SUMMAR Y
Tris and EDTA combined to form a homologue which has far greater chelating ability than EDTA alone. The weaker serine and $\mathrm{NH}_{4} \mathrm{Cl}$ homologues of EDTA replaced EDTA + tris in causing toxicity and permitting lysozyme lysis in Azotobacter vinelandii. Serine could effectively substitute for tris in these systems for Pseudomonas aeruginosa. These compounds had relatively little effect on Escherichia coli. The toxicity of EDTA + tris for these organisms could be alleviated by pre-incubation in physiological saline $(0 \cdot 15 \mathrm{M}-\mathrm{NaCl})$. Subsequent lysozyme lysis was prevented by this treatment. The removal of metals from $A$. vinelandii cysts by EDTA + tris was also inhibited. The EDTA + tris + metallo chelate complexes were inactivated (dissociated) by saline.
\end{abstract}

\section{INTRODUCTION}

Many Gram-negative organisms which are resistant to lysozyme will lyse when ethylenediaminetetra-acetic acid (EDTA) and tris buffer (2-amino-2-hydroxymethylpropane-1,3-diol) are also present in addition to lysozyme (Repaske, 1956, 1958; McQuillen, 1960a). Repaske first established a requirement for these compounds in this lytic system but did not determine the toxicity of the individual components. Socolofsky \& Wyss (1961) were able to rupture cysts of Azotobacter vinelandii by using EDTA and tris. The released 'central bodies' were not viable and were lysed by adding lysozyme. Goldschmidt \& Wyss (1966: to be published), while studying this toxic effect in greater detail, observed that the EDTA + tris system was toxic to vegetative organisms as well as to cysts even under conditions where cyst rupture did not occur (i.e. in $0.15 \mathrm{M}-\mathrm{NaCl}$ ). EDTA suspended in water or $0.025 \mathrm{M}-\mathrm{NaCl}$ also ruptured the cyst exine, but the central bodies remained viable under these conditions. They also found that various other substances such as amines, amino acids and $\mathrm{NH}_{4} \mathrm{Cl}$ could replace tris in producing toxicity in the presence of EDTA; these compounds also substituted for tris in the tris+EDTA+lysozyme system. These results are presented in the present paper. During this work, other bacteria were tested for their sensitivity to the EDTA + tris system (Goldschmidt, Goldschmidt \& Wyss, 1967). Repaske (1958) noted that Escherichia coli was sensitive to his lytic system. Goldschmidt et al. (1967) found that male strains of $E$. coli $(\mathrm{Hfr}$, male) were sensitive to the EDTA + tris system (65-95\% kill within 4 min.) while female strains and $E$. coli $\mathrm{B} / \mathrm{r}$ (which is ' $\mathrm{F}^{\circ}$ ' and does not mate) were not killed. There are many reports in the literature discussing differ-

* Present address: Department of Microbiology, Baylor University College of Medicine, Houston, Texas, 77025, U.S.A. 
ences in the surface configuration of male and female strains (Jacob \& Wollman, 1961; Hayes, 1964; Maccacaro, 1955; Maccacaro \& Comolli, 1956). Brinton, Gemski \& Carnahan (1964) indicated that maleness is probably not a property of the cell wall but of specific pili projecting from it. These differences might play a role in EDTA+tris toxicity and subsequent lysozyme lysis. For these reasons, strains of different sexuality were also tested for their sensitivity to the EDTA+ 'tris substitute' systems and subsequent lysozyme lysis under these conditions. Pseudomonas aeruginosa, which is very sensitive to EDTA, was also investigated.

\section{METHODS}

Media. Azotobacter vinelandii strain 12837 was grown at $33^{\circ}$ on Burk medium (Burk \& Lineweaver 1930 ) supplemented with $0.2 \%$ butanol (as sole carbon source), $0.01 \mathrm{~g}$. $\mathrm{MnCl}_{2} / 1$. and $2 \%$ agar. The various strains of Escherichia coli (obtained from Dr E. Goldschmidt) were grown in Difco Penassay broth at $37^{\circ}$. Pseudomonas aeruginosa strain 160 (obtained from Dr C. Graber) was grown in Difco Penassay broth at $28^{\circ}$.

Harvesting procedures. Bacteria grown on agar were scraped off, resuspended in various diluents, agitated, strained through sterile cheesecloth and washed 2-3 times at room temperature by alternate centrifugation and resuspension in fresh diluent. Fifteen minutes in a Serval anglehead centrifuge Model SPX at $1400 \mathrm{~g}$ sedimented the bacteria. Broth cultures were centrifuged and similarly washed.

Assay procedures. For the experiments concerned with EDTA toxicity and lysozyme lysis, organisms were suspended in the desired diluent and pipetted into optically calibrated sterile spectrophotometer tubes. The lytic agents were added so that the final volume of the reaction mixture was $4 \mathrm{ml}$. Lysozyme was always added immediately after EDTA. The action of EDTA and lysozyme was stopped by serial dilution in sterile $0.15 \mathrm{M}-\mathrm{NaCl}$. The dilutions of Azotobacter vinelandii were streaked on solid Burk medium and incubated at $33^{\circ}$. Escherichia coli and Pseudomonas aeruginosa were similarly plated on Difco Penassay agar and incubated at $37^{\circ}$ and $28^{\circ}$ respectively. Per cent survival was determined by comparing the number of surviving colonies with the appropriate untreated controls. The changes in extinction $(E)$ were determined by subtracting the extinction of the treated organism suspensions from that recorded for the untreated controls.

Extinction measurements. The Bausch and Lomb Spectronic 20, set at a wavelength of $600 \mathrm{~m} \mu$, was used to determine the extinction of suspensions.

Chemicals. The sodium salt of EDTA was dissolved in various diluents $(\mathrm{NaCl}$, $\mathrm{NH}_{4} \mathrm{Cl}$ serine, $\mathrm{H}_{2} \mathrm{O}$, etc.) depending upon the desired experimental conditions and adjusted to $\mathrm{pH} 8$ with $\mathrm{N}-\mathrm{HCl}$ and $\mathrm{N}-\mathrm{NaOH}$. Solutions of the sodium salt of dipicolinic acid (2,6-pyridinedicarboxylic acid:DPA) were similarly prepared. Tris was dissolved in de-ionized water and adjusted to $\mathrm{pH} 8$ with $\mathrm{N}-\mathrm{HCl}$. Lysozyme was dissolved in water or in the various diluents. EDTA, lysozyme and DPA were freshly prepared for each experiment and sterilized by millipore filtration. 


\section{RESULTS AND DISCUSSION}

Lysozyme lysis

The previous experiments of Goldschmidt \& Wyss (1966) with tris substitutes posed a series of questions: Could various amino acids or $\mathrm{NH}_{4} \mathrm{Cl}$ substitute for tris in preparing Azotobacter vinelandii, Pseudomonas aeruginosa and Escherichia coli for lysozyme lysis? Could these compounds similarly substitute for tris in causing EDTA toxicity in the latter organisms? If this occurred, was the toxicity also sex differentiated in E. coli as previously observed with EDTA + tris? (Goldschmidt et al. 1966). Could DPA substitute for EDTA in the lytic system?

The clearing of bacterial suspensions (measured quantitatively by the change in extinction) is commonly used to indicate the degree of lysis (Repaske, 1958; Socolofsky \& Wyss, 1961; Herzberg \& Green, 1964). Microscopic examination of our treated cultures supported these results. Lysis can be positively correlated with the decrease in extinction. As can be seen in Table $1, \mathrm{NH}_{4} \mathrm{Cl}$ could replace tris in the lytic EDTA + tris + lysozyme system for both Azotobacter vinelandii cysts and vegetative forms within the 4 min. experimental period. With the Escherichia coli strains, however (see Table 2), $\mathrm{NH}_{4} \mathrm{Cl}$ or serine could not effectively substitute for tris in this brief time. Very little toxicity was noted, regardless of sex, although serine was slightly more toxic than $\mathrm{NH}_{4} \mathrm{Cl}$ for the male strains. Only a slight decrease in extinction, if any, was noted when these compounds were substituted for tris.

\section{Table 1. Effect of various diluents on lysozyme lysis in Azotobacter vinelandii}

$24 \mathrm{hr}$ vegetative organisms and 14-day cysts washed twice and resuspended in the diluent. Final concentrations of reagents: $0.025 \mathrm{M}$-tris; $0.025 \mathrm{M}-\mathrm{NH}_{4} \mathrm{Cl} ; 0.25 \mathrm{mM}-\mathrm{EDTA}$; $100 \mu \mathrm{g}$. lysozyme. Reaction time 4 min., pH 8.0. The change in extinction for the cysts in EDTA is due to rupture of the exine (outer shell) but not the central body (equivalent to the vegetative form). It is the additional lysis of the central body that is reflected in the EDTA+lysozyme column.

\begin{tabular}{llcccc}
\multicolumn{1}{c}{ Cell type } & Diluent & $\begin{array}{c}\text { Survival } \\
\text { in EDTA } \\
(\%)\end{array}$ & $\overbrace{\text { EDTA }}$ & Change in extinction* \\
Vegetative & $\mathrm{H}_{2} \mathrm{O}$ & 65 & 0.040 & +0.015 & $\begin{array}{c}\text { EDTA+ } \\
\text { lysozyme }\end{array}$ \\
Cyst & $\mathrm{H}_{2} \mathrm{O}$ & 95 & 0.071 & 0.040 & 0.057 \\
Vegetative & Tris & 0.08 & 0.047 & 0.002 & 0.080 \\
Cyst & Tris & 0.01 & 0.294 & 0.035 & 0.464 \\
Vegetative & $\mathrm{NH}_{4} \mathrm{Cl}$ & 0.34 & 0.036 & 0.012 & 0.202 \\
Cyst & $\mathrm{NH}_{4} \mathrm{Cl}$ & 1.6 & 0.282 & 0.018 & 0.422
\end{tabular}

* The change in extinction represents a decrease compared to the untreated controls; an increase in extinction over that of the control is indicated by $a+$.

With Pseudomonas aeruginosa, serine could substitute for tris in preparing organisms for lysozyme lysis, but $\mathrm{NH}_{4} \mathrm{Cl}$ had no effect (see Table 3). An increase in molarity (from $0.025 \mathrm{M}$ to $0.05 \mathrm{M}$ ) increased both the amount of lysis obtained with serine and the speed of the reaction. There was no difference noted with $\mathrm{NH}_{4} \mathrm{Cl}$ at the higher molarity even after exposure for $1 \mathrm{hr}$.

It is important to note that lysozyme lysis of male, female and $\mathbf{B} / \mathbf{r}$ strains of Escherichia coli occurred regardless of the initial sensitivity to EDTA+tris when the 
tris + EDTA + lysozyme system was used. This will be discussed in greater detail later in this paper. Neu \& Heppel (1964) reported that E. coli B (similar to B/r) maintained a high degree of viability (60-90\%) when exposed to a sucrose + EDTA + tris mixture for $10 \mathrm{~min}$.

Table 2. Effect of various diluents on EDTA toxicity and lysozyme lysis in Escherichia coli

Organisms washed twice and resuspended in the diluent. Final concentrations of reagents: $0.025 \mathrm{M}$-tris; $0.025 \mathrm{M}-\mathrm{NH}_{4} \mathrm{Cl}$; $0.025 \mathrm{M}$-Serine; 0.25 mM-EDTA; $100 \mu \mathrm{g}$. lysozyme. Reaction time: 4 min. $\mathrm{pH} 8 \cdot 0$.

\begin{tabular}{|c|c|c|c|c|c|}
\hline \multirow[b]{2}{*}{ Strain } & \multirow[b]{2}{*}{ Diluent } & \multirow{2}{*}{$\begin{array}{c}\text { Survival } \\
\text { in EDTA } \\
(\%)\end{array}$} & \multicolumn{3}{|c|}{ Change in extinction* } \\
\hline & & & EDTA & lysozyme & $\begin{array}{l}\text { EDTA+ } \\
\text { lysozyme }\end{array}$ \\
\hline $\mathrm{F}^{-}$ & $\begin{array}{l}\text { Tris } \\
\mathrm{NH}_{4} \mathrm{Cl} \\
\text { Serine } \\
\mathrm{H}_{2} \mathrm{O}\end{array}$ & $\begin{array}{r}90 \\
85 \\
104 \\
102\end{array}$ & $\begin{array}{l}0 \\
0 \\
0.027 \\
0.014\end{array}$ & $\begin{array}{c}0.016 \\
0 \\
+0.068 \\
+0.180\end{array}$ & $\begin{array}{r}0.522 \\
0.033 \\
+0.089 \\
+0.124\end{array}$ \\
\hline $\mathrm{F}^{+}$ & $\begin{array}{l}\text { Tris } \\
\mathrm{NH}_{4} \mathrm{Cl} \\
\text { Serine } \\
\mathrm{H}_{2} \mathrm{O}\end{array}$ & $\begin{array}{r}10 \\
100 \\
85 \\
100\end{array}$ & $\begin{array}{r}0.012 \\
0.036 \\
0.029 \\
+0.002\end{array}$ & $\begin{array}{r}0.006 \\
0.036 \\
+0.013 \\
+0.029\end{array}$ & $\begin{array}{l}0.441 \\
0.036 \\
0.054 \\
0.007\end{array}$ \\
\hline $\mathrm{Hfr}$ & $\begin{array}{l}\text { Tris } \\
\mathrm{NH}_{4} \mathrm{Cl} \\
\text { Serine } \\
\mathrm{H}_{2} \mathrm{O}\end{array}$ & $\begin{array}{r}7 \\
100 \\
69 \\
103\end{array}$ & $\begin{array}{l}0.046 \\
0.002 \\
0.029 \\
0.014\end{array}$ & $\begin{array}{l}+0.008 \\
+0.016 \\
+0.081 \\
+0.101\end{array}$ & $\begin{array}{r}0.316 \\
0.075 \\
+0.106 \\
+0.146\end{array}$ \\
\hline $\mathrm{B} / \mathrm{r}$ & $\begin{array}{l}\text { Tris } \\
\mathrm{NH}_{4} \mathrm{Cl} \\
\text { Serine } \\
\mathrm{H}_{2} \mathrm{O}\end{array}$ & $\begin{array}{r}95 \\
82 \\
80 \\
100\end{array}$ & $\begin{array}{l}0.067 \\
0.006 \\
0.014 \\
0.003\end{array}$ & $\begin{array}{l}+0.068 \\
+0.005 \\
+0.088 \\
+0.124\end{array}$ & $\begin{array}{r}0.308 \\
+0.003 \\
+0.089 \\
+0.097\end{array}$ \\
\hline
\end{tabular}

* The change in extinction represents a decrease compared to untreated controls. An increase in extinction compared to the controls is indicated by $a+$.

The female strains of Escherichia coli eventually showed a decrease in viability after a lengthy exposure to EDTA + tris. When various strains were plated $2-4 \mathrm{hr}$ later viability had decreased 30-60\%. During this time, viability in the males had decreased below $5 \%$. Therefore, both female and male strains were incubated for $2 \mathrm{hr}$ with $\mathrm{H}_{2} \mathrm{O}$ tris, serine or $\mathrm{NH}_{4} \mathrm{Cl}$ and the various components of the lytic system (instead of the usual $4 \mathrm{~min}$.). These data are presented in Table 4 . There was no delayed lysis when $\mathrm{NH}_{4} \mathrm{Cl}$ was substituted for tris, regardless of this longer exposure time. However, a considerable amount of lysis occurred in the absence of lysozyme when both male and female strains were incubated in EDTA + tris alone for this length of time. This explains the gradual loss in viability of the female strains. There was also some lysis with serine alone after a lengthy exposure $(2 \mathrm{hr})$. Under these conditions, however, no additional lysis due to lysozyme was observed.

Pseudomonas aeruginosa was also lysed by $0.025 \mathrm{M}$-tris +EDTA. A small degree of lysis was observed at $4 \mathrm{~min}$. However, longer exposure resulted in almost the same amount of lysis as found in the lysozyme system (see Table 3). It is also interesting to note that a higher molarity of tris $(0.05 \mathrm{M})$ in combination with EDTA induced considerable lysis within the first 4 min. Herzberg \& Green (1964) reported some lysis of 
Salmonella typhimurium with EDTA + tris alone but found that far greater lysis occurred when lysozyme was also present in the system. Similar results with $P$. aeruginosa have been reported by Eagon \& Carson (1965).

\section{Table 3. Effect of various diluents and time of exposure on lysozyme lysis in Pseudomonas aeruginosa}

24-hr shake-culture organisms were washed twice and resuspended in the diluent. Final concentration of reagents: diluents as shown in the table; 0.25 mM-EDTA; $100 \mu \mathrm{g}$. lysozyme. $\mathrm{pH} 8 \cdot 0$.

\begin{tabular}{|c|c|c|c|c|c|c|}
\hline \multirow[b]{2}{*}{ Diluent } & \multirow[b]{2}{*}{$\begin{array}{l}\text { Conc. } \\
\text { (M) }\end{array}$} & \multirow[b]{2}{*}{$\begin{array}{l}\text { Time of } \\
\text { exposure } \\
\text { (min.) }\end{array}$} & \multirow[b]{2}{*}{ Control } & \multicolumn{3}{|c|}{ Change in extinction* } \\
\hline & & & & EDTA & Lysozyme & $\begin{array}{l}\text { EDTA + } \\
\text { Lysozyme }\end{array}$ \\
\hline \multirow[t]{2}{*}{ Tris } & 0.025 & $\begin{array}{r}4 \\
60 \\
120 \\
180 \\
240\end{array}$ & $\begin{array}{l}0 \\
0.033 \\
0.058 \\
0.042 \\
0.039\end{array}$ & $\begin{array}{l}0.078 \\
0.158 \\
0.182 \\
0.294 \\
0.330\end{array}$ & $\begin{array}{r}+0.038 \\
+0.024 \\
+0.050 \\
0.005 \\
0.006\end{array}$ & $\begin{array}{l}0.312 \\
0.337 \\
0.331 \\
0.350 \\
0.352\end{array}$ \\
\hline & 0.05 & $\begin{array}{r}4 \\
60\end{array}$ & $\begin{array}{l}0 \\
0 \cdot 061\end{array}$ & $\begin{array}{l}0 \cdot 133 \\
0 \cdot 190\end{array}$ & $\begin{array}{l}0.056 \\
0.021\end{array}$ & $\begin{array}{l}0.338 \\
0.316\end{array}$ \\
\hline \multirow[t]{2}{*}{ Serine } & 0.025 & $\begin{array}{r}4 \\
10 \\
60\end{array}$ & $\begin{array}{l}0 \\
0.013 \\
0.010\end{array}$ & $\begin{array}{l}0.007 \\
0.007 \\
0.015\end{array}$ & $\begin{array}{r}+0.062 \\
+0.056 \\
0.046\end{array}$ & $\begin{array}{l}0.006 \\
0.083 \\
0.194\end{array}$ \\
\hline & 0.050 & $\begin{array}{r}4 \\
50\end{array}$ & $\begin{array}{l}0 \\
0\end{array}$ & $\begin{array}{l}0.017 \\
0.040\end{array}$ & $\begin{array}{l}+0.033 \\
+0.027\end{array}$ & $\begin{array}{l}0.122 \\
0.219\end{array}$ \\
\hline \multirow[t]{2}{*}{$\mathrm{NH}_{4} \mathrm{Cl}$} & 0.025 & $\begin{array}{r}4 \\
60\end{array}$ & $\begin{array}{l}0 \\
0.013\end{array}$ & $\begin{array}{l}0.014 \\
0.017\end{array}$ & $\begin{array}{l}0 \\
0.008\end{array}$ & $\begin{array}{l}0.022 \\
0.051\end{array}$ \\
\hline & 0.050 & $\begin{array}{r}4 \\
50\end{array}$ & $\begin{array}{l}0 \\
0.019\end{array}$ & $\begin{array}{r}0.004 \\
+0.007\end{array}$ & $\begin{array}{r}0.019 \\
+0.019\end{array}$ & $\begin{array}{l}0.058 \\
0.076\end{array}$ \\
\hline $\mathrm{H}_{2} \mathrm{O}$ & & $\begin{array}{r}4 \\
60 \\
90\end{array}$ & $\begin{array}{l}0 \\
0.004 \\
0.028\end{array}$ & $\begin{array}{l}+0.026 \\
+0.014 \\
+0.064\end{array}$ & $\begin{array}{r}+0.074 \\
+0.112 \\
0.026\end{array}$ & $\begin{array}{l}0.028 \\
0.057 \\
0.030\end{array}$ \\
\hline
\end{tabular}

* The change in extinction represents a decrease compared to the untreated controls at that time period; an increase in extinction over that of the control is indicated by a + . The change in extinction of the control represents the change from the initial (zero hour) reading.

\section{Effect of dipicolinic acid (DPA)}

DPA, another chelating agent, was tested for its ability to substitute for EDTA in inducing lysozyme lysis in these organisms. Other than the changes in optical density resulting from the initial rupture of the Azotobacter vinelandii cyst exine by DPA, there was no subsequent lysis of the central bodies when either the DPA + tris + lysozyme or $\mathrm{DPA}+\mathrm{NH}_{4} \mathrm{Cl}+$ lysozyme systems were tested. Similarly, Escherichia coli and Pseudomonas aeruginosa were not lysed when DPA replaced EDTA. Repaske (1958) had tested several other chelating agents such as versenol, 8-hydroxyquinoline and $O$ phenanthroline and noted an 'unusual specificity' for EDTA in his system. Gray \& Wilkinson (1965a) also observed a similar specificity with $P$. aeruginosa. Since all the data comparing these organisms indicated that $A$. vinelandii and $P$. aeruginosa were somewhat more sensitive than $E$. coli, the degree of lysozyme lysis with the DPA system was also observed after a $1 \mathrm{hr}$ exposure. No significant increase in lysis was noted with DPA + tris or DPA + lysozyme + tris after this longer exposure. One can 
Table 4. Effect of time on EDTA and lysozyme lysis of Escherichia coli

Organisms were washed twice and resuspended in the diluent. Final concentrations of reagents: $0.025 \mathrm{M}$-tris; $0.025 \mathrm{M}-\mathrm{NH}_{4} \mathrm{Cl} ; 0.025 \mathrm{M}$-serine; 0.25 mM-EDTA; $100 \mu \mathrm{g}$. lysozyme. pH 8.0.

$\begin{array}{cclccc}\text { Sime of } & \begin{array}{c}\text { Change in extinction* } \\ \text { Strain } \\ \text { exposure } \\ \text { (min.) }\end{array} & \text { Diluent } & \text { EDTA } & \text { Lysozyme } & \begin{array}{r}\text { EDTA } \\ \text { lysozyme }\end{array} \\ & 4 & \text { Tris } & 0.019 & 0.022 & 0.323 \\ & 120 & \text { Tris } & 0.236 & 0.026 & 0.402 \\ & 4 & \text { Serine } & 0.027 & +0.068 & +0.089 \\ & 120 & \text { Serine } & 0.106 & +0.051 & 0.106 \\ & 4 & \mathrm{NH}_{4} \mathrm{Cl} & +0.007 & +0.001 & 0.055 \\ & 120 & \mathrm{NH}_{4} \mathrm{Cl} & +0.008 & 0.018 & 0.054 \\ & 4 & \mathrm{H}_{2} \mathrm{O} & 0.014 & +0.180 & +0.124 \\ \mathrm{Hfr} & 120 & \mathrm{H}_{2} \mathrm{O} & 0.023 & +0.218 & +0.063 \\ & 4 & \text { Tris } & +0.008 & 0.024 & 0.219 \\ & 120 & \text { Tris } & 0.164 & 0.024 & 0.264 \\ 4 & \text { Serine } & 0.029 & +0.081 & +0.106 \\ & 120 & \text { Serine } & 0.202 & +0.034 & 0.079 \\ 4 & \mathrm{NH}_{4} \mathrm{Cl} & 0.002 & +0.016 & 0.075 \\ & 120 & \mathrm{NH}_{4} \mathrm{Cl} & 0.007 & +0.011 & 0.079 \\ 4 & \mathrm{H}_{2} \mathrm{O} & 0.014 & +0.101 & +0.146 \\ & 120 & \mathrm{H}_{2} \mathrm{O} & 0.029 & +0.222 & +0.080\end{array}$

* The change in extinction represents a decrease compared to the untreated controls. An increase in extinction over that of the control is indicated by a + .

conclude, therefore, that DPA cannot substitute for EDTA in preparing these organisms for lysozyme lysis.

\section{Chelating ability of EDTA+tris}

According to many reports in the literature (McQuillen, 1960 $a$; Weidel, Frank \& Martin, 1960; Herzberg \& Green, 1964) the resistance of Gram-negative organisms to lysozymelysis is due to the fact that the mucopolypeptide substrate is not accessible to the enzyme because the cell wall structure is more complex than in Gram-positive bacteria. The role of EDTA in mediating lysozyme lysis lies in its ability as a chelating agent to 'uncover' the mucopolypeptide layer either by removal of interfering ions or changing the surface charge or configuration. Once this has been accomplished, lysozyme can reach its substrate and lyse the cell walls (Weidel et al. 1960; Herzberg \& Green, 1964; Voss, 1965). Leive $(1965 a, b)$ reported that EDTA treatment of Escherichia coli caused non-specific increases in permeability to such diverse compounds as actinomycin, $o$-nitrophenyl-galactoside and carbamyl phosphate. Other data of Goldschmidt \& Wyss (1966: to be published) indicated that tris can act as a donor group to form a homologue with EDTA resulting in a more powerful chelating agent than EDTA alone. Martell \& Calvin (1953a) also presented evidence for the increased stability and heightened activity of such 'EDTA-complexes' or 'homologues'.

Preliminary emission spectroscopic data (see Table 5) indicated that the removal of metals and subsequent toxicity of EDTA for Azotobacter vinelandii cysts was greatly influenced by the diluent used in association with EDTA. Magnesium, manganese and calcium were the metals affected to the greatest extent. In brief, EDTA + tris removed very large amounts of these three metals (the organisms were almost com- 
pletely depleted and were not viable). No toxicity was observed in the absence of tris although magnesium was removed from the cysts in the $\mathrm{H}_{2} \mathrm{O}+$ EDTA system (resulting only in the rupture of the cyst exine). Lysozyme lysis did not occur under these conditions. Eagon \& Carson (1965) also reported the removal of calcium and magnesium from isolated cell walls of Pseudomonas aeruginosa when treated with tris + EDTA.

\section{Table 5. Effect of various diluents on the removal of metals from Azotobacter vinelandii cysts by EDTA}

14-day cysts washed twice and resuspended in the diluent. Final concentration of reagents: $0.025 \mathrm{M}$-tris; $0.15 \mathrm{M}-\mathrm{NaCl}$; $0.25 \mathrm{mm-EDTA;} 100 \mu \mathrm{g}$. lysozyme. Reaction time: $4 \mathrm{~min}$. Emission spectrographs were obtained as follows. Treated cyst suspensions were centrifuged after EDTA treatment. The cysts were then placed in graphite cups, dried quickly and burned in an arc. The resulting spectrum was photographed. Metal concentrations were determined by density comparison with controls run on untreated cysts at various wave lengths on the plates. The degree of metal removal is indicated by $a+$.

\begin{tabular}{lcccc} 
& \multicolumn{4}{c}{ Diluents } \\
\cline { 2 - 4 } & Tris & $\mathrm{H}_{2} \mathrm{O}$ & $\mathrm{NaCl}$ & $\mathrm{NaCl}+$ tris \\
Metals & ++++ & ++ & 0 & + \\
Magnesium & ++++ & 0 & 0 & + \\
$\quad$ Calcium & ++++ & 0 & 0 & + \\
Toxicity (\%) & 100 & 95 & 0 & 0 \\
$\quad$ Cyst rupture & 0.02 & 100 & 100 & $2 \cdot 0$ \\
Survival & $90-100$ & None & None & $5-10$
\end{tabular}

$++++=$ No spectral line evident on spectrogram; $0=$ spectral line same density as control.

\section{Effect of $\mathrm{NaCl}$ on metal removal, EDTA toxicity and lysozyme lysis}

According to reports in the literature the addition of salts render metallo + EDTA complexes unstable (Fleming, Ordal \& Steinrauf, 1963; Wolin \& Reichelt, 1964). Goldschmidt \& Wyss (1966) also observed this effect with Azotobacter vinelandii. As can be seen in Table 5, very little metal removal was noted with EDTA $+\mathrm{NaCl}$ $(0.15 \mathrm{M})$ and metals were removed to a much lesser degree with a EDTA+tris $+\mathrm{NaCl}$ system without previous incubation in $\mathrm{NaCl}$, as compared to EDTA+tris alone. Lysozyme lysis was largely inhibited under these conditions even though the cysts were killed. When either $A$. vinelandii cysts or vegetative forms were shaken in $0 \cdot 15 \mathrm{M}$ $\mathrm{NaCl}$ for several hours before exposure to EDTA+tris, $90 \%$ survival resulted (see Table 6). Evidently, the increased incubation time in saline either allowed $\mathrm{NaCl}$ to permeate the cells or build up in high enough concentration at the cell surface as completely to dissociate or inactivate the metallo+EDTA + tris homologue. Gray \& Wilkinson (1965a) reported an increase in survival of Pseudomonas aeruginosa from $0.01 \%$ to $50 \%$ when organisms were exposed to EDTA after washing in a $0.2 \mathrm{M}$ borate buffer instead of a $0.05 \mathrm{M}$-borate buffer. Their data might be explained on the basis of the dissociation of EDTA complexes at the higher molarity.

Escherichia coli $\mathrm{B} / \mathrm{r}$ and $\mathrm{Hfr}$ strains and Pseudomonas aeruginosa were exposed to $0.15 \mathrm{M}-\mathrm{NaCl}$ for short periods of time in the presence and absence of tris. The degree of EDTA + tris toxicity and subsequent lysozyme lysis were observed. These data are reported in Table 6. 
The addition of $0 \cdot 15 \mathrm{M}-\mathrm{NaCl}$ to the EDTA + tris lysozyme system greatly inhibited lysozyme lysis in both strains of Escherichia coli as well as Azotobacter vinelandii. No lysis occurred in the $A$. vinelandii or B/r strains and only $10-30 \%$ lysis was observed with the Hfr strain. Initial lysozyme lysis of Pseudomonas aeruginosa was also greatly inhibited when $0 \cdot 15 \mathrm{M}-\mathrm{NaCl}$ was added (Table 6). Longer exposures (30 min. to several

Table 6. Effect of $\mathrm{NaCl}$ on EDTA + tris toxicity and subsequent lysozyme lysis

24-hr shake-culture organisms and 14-day cysts were washed twice and resuspended as indicated unless incubated between these steps in: (a) $0.15 \mathrm{M}-\mathrm{NaCl}$ for $15 \mathrm{~min}$.; (b) 0.15 $\mathrm{M}-\mathrm{NaCl}+0.025 \mathrm{M}$-tris for $15 \mathrm{~min}$; $(c) 0.15 \mathrm{M}-\mathrm{NaCl}$ for $4 \mathrm{hr}$. Final concentrations: 0.025 mM-EDTA, $100 \mu \mathrm{g}$. lysozyme. $\mathrm{pH} 8 \cdot 0$. Reaction time: $4 \mathrm{~min}$.

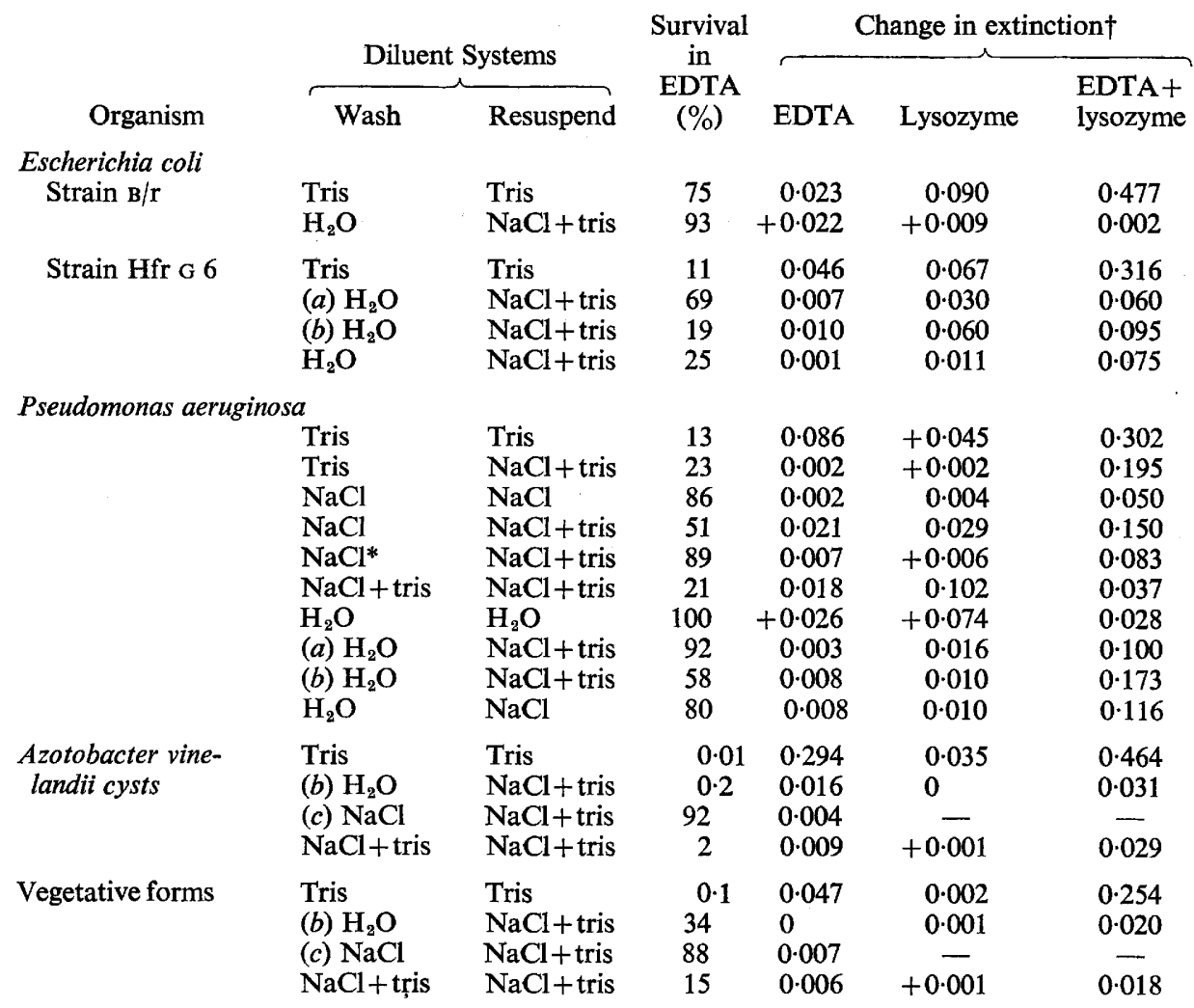

* Organisms washed twice in $0.3 \mathrm{M}-\mathrm{NaCl}$.

+ The change in extinction represents a decrease compared to the untreated controls. An increase in extinction over that of the controls is indicated by a + .

hours) resulted in lysis in some cases, particularly with organisms washed in water or tris or pre-incubated in $\mathrm{NaCl}+$ tris. This lysis was actually not as extensive as that observed in the absence of saline; $0.3 \mathrm{M}-\mathrm{NaCl}$ afforded greater protection against EDTA + tris toxicity than $0 \cdot 15 \mathrm{M}-\mathrm{NaCl}$. Evidently the degree of dissociation of the EDTA + tris homologue in $0 \cdot 15 \mathrm{M}-\mathrm{NaCl}$ was not high enough to prevent eventual lysozyme lysis in $P$. aeruginos $a$ and higher concentrations might be required. However, lysis by tris + EDTA alone was completely inhibited in every case by $0 \cdot 15 \mathrm{M}-\mathrm{NaCl}$ even after an exposure of several hours. 
As can be seen in Table 6, when the Hfr strain of Escherichia coli (harvested in $\mathrm{H}_{2} \mathrm{O}$ ) was incubated for $15 \mathrm{~min}$. in $0.15 \mathrm{M}-\mathrm{NaCl}$ before the other components were a dded, the survival in EDTA + tris + $\mathrm{NaCl}$ increased from 11 to $69 \%$ while subsequent lysozyme lysis was $90 \%$ inhibited. No doubt longer pre-incubation would have resulted in even greater survival. The $\mathrm{B} / \mathrm{r}$ strain also showed an increased survival (from $75 \%$ to $93 \%$ ) under these conditions. When tris was also present in the Hfr pre-incubation mixture, only an $8 \%$ increase in survival was noted, while lysis was $70 \%$ inhibited. An increase to $25 \%$ survival was found when these organisms were exposed to this system without any previous incubation; here lysozyme lysis was still $(77 \%)$ inhibited. Thus, the degree of survival depended largely upon the conditions of pre-incubation with $\mathrm{NaCl}$, while lysozyme lysis was inhibited as long as saline was present regardless of pretreatment. The data with Pseudomonas aeruginosa indicates a similar effect of $0.15 \mathrm{M}-\mathrm{NaCl}$ in increasing the survival of pseudomonads under these conditions (Table 6).

As already mentioned, EDTA + tris toxicity is sex-differentiated in Escherichia coli. However, subsequent lysis occurred when lysozyme was added (in the absence of $\mathrm{NaCl}$ ) regardless of mating characteristics. This is another indication that the initial action of EDTA + tris is at the cell surface. Thus, the manner in which EDTA+tris 'prepares' organisms for lysozyme lysis does not necessarily produce lethality, since female and $\mathrm{B} / \mathrm{r}$ strains are not killed by this step although they still become as susceptible to lysozyme lysis as the males. The toxicity observed with the male strains of E. coli, with Pseudomonas aeruginosa and Azotobacter vinelandii (which occurs within 4 min.), must be due to an additional action of EDTA + tris on other sensitive structures presumably within the organism or at the cytoplasmic membrane. There are many reports in the literature about the toxic effect of EDTA in the functioning of chromosomes and RNA (Kaufman \& McDonald, 1957), on the inhibition of metalloenzyme functions and on causing death by metal starvation (reviewed by Martell \& Calvin, $1953 \mathrm{~b}$ ), etc. As previously mentioned, female strains of $E$. coli have surface characteristics different from those of the males (i.e. they behave as if they were more negatively charged and lack male specific pili). These differences may in some manner prevent additional EDTA + tris penetration to sensitive intracellular targets. In the males, evidently this penetration is not prevented since an $80-90 \%$ kill was observed within $4 \mathrm{~min}$. If the tris +EDTA homologue penetrated underneath the cell wall of the males via the hollow pilus, it would be very difficult to stop the toxic action by the usual method of adding $\mathrm{NaCl}$ to dilute and dissociate the complex. The continued intimate association of EDTA + tris would result in death probably by membrane damages, effect on chromosomes, etc. According to Dr C. C. Brinton (personal communication) this theory is entirely feasible.

The fact that $\mathrm{NH}_{4} \mathrm{Cl}$ and/or amino acids can substitute for tris in producing toxicity to Azotobacter vinelandii and Pseudomonas aeruginosa but are not particularly effective with Escherichia coli indicates further differences in surface characteristics and sensitivity among these organisms. 'The sensitivity of an organism to EDTA should be dependent on the nature and strength of the bonds formed between the metal and the metal-binding components of the cell wall' (Gray \& Wilkinson, 1965b). These authors considered $E$. coli to be only 'moderately sensitive' as compared with the 'exceptional' EDTA sensitivity of several other organisms such as $P$. aeruginosa.

Metals (both within and on the surface) are probably bound more tightly in 
Escherichia coli. Serine+EDTA permitted lysozyme lysis within a few minutes of Azotobacter vinelandii and Pseudomonas aeruginosa but not of $E$. coli. A long exposure of several hours to tris or serine (+EDTA) was also needed here before lysis occurred in the absence of lysozyme, while the tris and serine homologues lysed $P$. aeruginosa after a brief exposure. These data indicated that the serine+EDTA homologue was a weaker complexing agent than tris +EDTA. The relative ineffectiveness of $\mathrm{NH}_{4} \mathrm{Cl}$ for $E$. coli and $P$. aeruginosa indicated that it formed the weakest homologue of the three with EDTA.

The fact that $\mathrm{NH}_{4} \mathrm{Cl}$ and serine formed weaker homologues with EDTA than tris might explain their failure to affect Escherichia coli to the same extent. According to Gray \& Wilkinson (1965a), Pseudomonas aeruginosa is even sensitive to EDTA in borate buffer. The inhibitory effect of $\mathrm{NaCl}$ on EDTA + tris toxicity and subsequent lysozyme lysis also indicates the importance of the EDTA + tris complex in causing toxicity and preparing organisms for lysozyme lysis by virtue of its chelating activities. This supports the many reports in the literature which claim that the activity of EDTA is due primarily to its ability to form chelates. The EDTA + tris lysozyme system is commonly used in forming spheroplasts of Gram-negative organisms (McQuillen, $1960 a$ ). These spheroplasts can carry on limited synthetic functions such as enzyme synthesis and phage production, etc. (even an organism killed by ultraviolet radiation can carry out the latter function). According to Frazer (quoted in McQuillen, 1960 b), however, these EDTA + tris spheroplasts never revert or divide and are 'nonviable' even though active synthetically.

This work was supported in part by a National Institutes of Health Postdoctoral Training Grant MG 600, Division of General Medical Sciences.

The authors thank Mr W. B. Wardlow (Texas State Health Laboratories) for the emission spectrograph data, and Mrs Chiasato Kusaka for excellent technical assistance.

\section{REFERENCES}

Brinton, C. C., Gemski, P. \& Carnahan, J. (1964). A new type of bacterial pilus genetically controlled by the fertility factor of $E$. coli $\mathrm{K} 12$ and its role in chromosome transfer. Proc. natn. Acad. Sci. U.S.A. 52, 776.

Burk, D. \& Lineweaver, H. (1930). The influence of fixed nitrogen on Azotobacter. J. Bact. 19, 389.

EAGON, R. G. \& CARSON, K. J. (1965). Lysis of cell walls and intact cells of Pseudomonas aeruginosa by ethylenediaminetetra-acetic acid and by lysozyme. Can. J. Microbiol. 11, 193.

Fleming, H. P., Ordal, Z. J. \& Steinrauf, L. K. (1963). Chelation properties of dipicolinic acid and effects of ionic strength on chelate stability and bacterial spore germination. Bact. Proc. p. 24.

GoldsCHMIDT, M. C. \& WYss, O. (1966). Chelation effects on Azotobacter cells and cysts. J. Bact. 91, 120.

Goldschmidt, M. C., Goldschmidt, E. P. \& Wyss, O. (1967). Differences in toxicity of EDTA among mating types of Escherichia coli. Can. J. Microbiol. (in the Press).

Gray, G. W. \& Wilkinson, S. G. (1965 a). The action of ethylenediaminetetra-acetic acid on Pseudomonas aeruginosa. J. appl. Bact. 28, 153.

Gray, G. W. \& Wilkinson, S. G. (1965b). The effect of ethylenediaminetetra-acetic acid on the cell walls of some Gram-negative bacteria. J. gen. Microbiol. 39, 385.

HAYES, W. (1964). The Genetics of Bacteria and their Viruses, p. 567, New York: John Wiley and Sons Inc.

Herzberg, M. \& Green, J. H. (1964). Composition of cell walls of Salmonella. J. gen. Microbiol. $35,421$.

JACOB, F. \& Wollman, E. (1961). Sexuality and the Genetics of Bacteria, p. 118. New York and London: Academic Press Inc.

KaufMAN, B. P. \& MCDONALD, M. R. (1957). The nature of the changes effected in chromosomal materials by the chelating agent EDTA. Proc, natn. Acad. Sci. U.S.A. 43, 262. 
LEIVE, L. (1965a). A non-specific increase in permeability in Escherichia coli produced by EDTA. Proc. natn. Acad. Sci. U.S.A. 53, 745.

LEIVE, L. (1965b). Actinomycin sensitivity in Escherichia coli produced by EDTA. Biochem. biophys. Res. Comm. 18, 13.

MACCACARO, G. A. (1955). Cell surface and fertility in Escherichia coli. Nature, Lond. 176, 125.

MACCACARo, G. A. \& Comolli, R. (1956). Surface properties correlated with sex compatibility in Escherichia coli. J. gen. Microbiol. 15, 121.

Martell, A. E. \& Calvin, M. (1953a). Chemistry of the Metal Chelate Compounds, p. 141. New York: Prentice Hall, Inc.

Martell, A. E. \& Calvin, M. (1953b). Chemistry of the Metal Chelate Compounds, p. 499. New York: Prentice Hall, Inc.

MCQuillen, K. (1960a). Bacterial protoplasts. In The Bacteria. Ed. by I. C. Gunsalus and R. Y. Stanier, vol. 6, p. 249. New York and London: Academic Press Inc.

McQuillen, K. (1960 b). Bacterial protoplasts. In The Bacteria. Ed. by I. C. Gunsalus and R. Y. Stanier, vol. 6, p. 345. New York and London: Academic Press Inc.

NeU, H. C. \& HEPPEL, L. A. (1964). On the surface localization of enzymes in Escherichia coli. Biochem. biophys. Res. Comm. 17, 215.

REPASKe, R. (1956). Lysis of gram-negative bacteria by lysozyme. Biochim. biophys. Acta 22, 189.

REPASKE, R. (1958). Lysis of gram-negative organisms and the role of versene. Biochim. biophys. Acta 30, 225.

SocolofSKy, M. D. \& Wyss, O. (1961). Cysts of Azotobacter. J. Bact. 81, 946.

Voss, J. G. (1965). Lysozyme lysis of gram-negative bacteria without production of spheroplasts. J. gen. Microbiol. 35, 313.

Weidel, W., Frank, H. \& Martin, H. H. (1960). The rigid layer of the cell wall of Escherichia coli strain B. J. gen. Microbiol. 22, 158.

Wolin, M. J. \& Reichelt, E. C. (1964). Lysis of Vibrio succinogenes by EDTA or lysozyme. Bact. Proc. p. 32. 